\title{
Sildenafil citrate for the treatment of erectile dysfunction in men with Type II diabetes mellitus
}

\author{
A. J.M. Boulton ${ }^{1}$, J-L.Selam ${ }^{2}$, M.Sweeney ${ }^{3}$, D.Ziegler ${ }^{4}$ \\ ${ }^{1}$ University of Manchester, Manchester, United Kingdom \\ ${ }^{2}$ Hotel Dieu Hospital, Paris, France \\ ${ }^{3}$ Pfizer Inc, New York, NY, USA \\ ${ }^{4}$ German Diabetes Research Institute, Heinrich-Heine-University, Düsseldorf, Germany
}

\section{Abstract}

Aims/hypothesis. Ninety percent of all men with diabetes have Type II (non-insulin-dependent) diabetes mellitus, and erectile dysfunction (ED) is common in this patient group. This study evaluated the effects of sildenafil on men with erectile dysfunction and Type II diabetes and compared the results with glycated haemoglobin concentrations and chronic diabetic complications.

Methods. Patients (mean age, 59 years) in this double-blind, placebo-controlled trial were randomised to sildenafil $(25-100 \mathrm{mg} ; n=110)$ or matching placebo $(n=109)$ for 12 weeks. Primary criteria for efficacy included questions 3 (achieving an erection) and 4 (maintaining an erection) from the International Index of Erectile Function (IIEF, score range, 0-5). Secondary outcome measures included a global efficacy question (GEQ), patient event logs, a life satisfaction checklist, and the remaining IIEF questions.

Results. After 12 weeks, the mean scores for questions 3 and 4 had improved significantly in patients receiving sildenafil $(3.42 \pm 0.23$ and $3.35 \pm 0.24)$ com- pared with placebo $(1.86 \pm 0.22$ and $1.84 \pm 0.23$; $p<0.0001)$. Similarly, the GEQ score was higher in the sildenafil $(64.6 \%)$ than the placebo group $(10.5 \%)$. Even when correlating efficacy with glycated haemoglobin concentrations $(\leq 8.3 \%$ or $>8.3 \%$, the median concentration found in this study) or the number of diabetic complications $(0$ or $\geq 1)$, the mean scores for the GEQ and questions 3 and 4 from the IIEF remained higher for all the sildenafil groups compared with the placebo groups $(p<0.0001)$.

Conclusion/interpretation. Sildenafil was well-tolerated and effective in improving erectile dysfunction in men with Type II diabetes, even in patients with poor glycaemic control and chronic complications. [Diabetologia (2001) 44: 1296-1301]

Keywords Type II diabetes mellitus, glycaemic control, diabetic neuropathies, erectile dysfunction, vasculogenic erectile dysfunction, cyclic GMP-dependent phosphodiesterase, phosphodiesterase inhibitor, quality of life.
Diabetes mellitus is very common, with Type II (noninsulin-dependent) diabetes mellitus accounting for

Received: 20 April 2001 and in revised form: 16 July 2001

Corresponding author: Professor A.J.M. Boulton, Department of Medicine, Manchester Royal Infirmary, Oxford Road, Manchester, M13 9WL, United Kingdom, e-mail: ajmb@fs1.cmht.nwest.nhs.uk

Abbreviations: ED, erectile dysfunction; IIEF, International Index of Erectile Dysfunction; GEQ, global efficacy question; PDE, phosphodiesterase; cGMP, cyclic guanosine monophosphate; AE, adverse event.
$90 \%$ to $95 \%$ of the diagnosed patients [1]. A frequent complication of diabetes is erectile dysfunction (ED), with an estimated prevalence of $20 \%$ to $85 \%$ (ranging from mild to complete ED) [2], which occurs at an earlier age than in non-diabetic men. In the Massachusetts Male Aging study [3], men with treated diabetes had an age-adjusted prevalence of complete ED (no erections) of $28 \%$, which was approximately three times higher than the prevalence of complete ED observed in the entire sample of men $(10 \%)$.

Although ED in patients with diabetes is often complex and can be caused by several mechanisms 
- including vascular disease, autonomic neuropathy, hormone imbalance, and psychogenic factors - neuropathy and/or vascular disease seem to be the most frequent causes of ED in diabetic men [4]. The risk of ED increases with a longer duration of diabetes and with metabolic indices of inadequate diabetes control (e.g., increased blood glucose and glycated haemoglobin $\left[\mathrm{HbA}_{1 \mathrm{c}}\right]$ concentrations) [5].

There is a large degree of overlap between conditions typically associated with diabetes and risk factors for ED, namely, vascular disease, treated or untreated hypertension, neuropathy, and obesity which are all markedly more common in diabetic patients than in non-diabetic control subjects [6]. The incidence of diabetic microvascular complications, such as retinopathy, nephropathy, and neuropathy, can be reduced considerably by blood glucose control, whereas the risk of microvascular and macrovascular complications in this patient group can be reduced by normalising blood pressure [7].

Treatment options for men with ED have advanced considerably during the past 10 to 15 years and include intracavernous prostaglandin injections [8], vacuum constriction therapy [9], and transurethral alprostadil pellets [10]. However, efficacy and long-term satisfaction with these treatment options have not been optimal.

Sildenafil citrate, the first oral therapeutic agent for the treatment of ED [11], is a potent and selective inhibitor of cyclic guanosine monophosphate (cGMP)-specific phosphodiesterase type 5 (PDE5), the predominant isozyme metabolising cGMP in the corpus cavernosum [12]. Penile erection depends on relaxation of corpora cavernosa smooth muscle. In response to sexual stimuli, cavernous nerves and endothelial cells release nitric oxide, which stimulates formation of cGMP via guanylate cyclase. By selectively inhibiting cGMP catabolism in cavernosal smooth muscle cells, sildenafil restores the erectile response to sexual stimulation without causing erections in the absence of such stimulation [11].

We assessed the efficacy and safety of sildenafil in men with Type II diabetes and ED, with particular emphasis on glycaemic control (e.g., the concentration of $\mathrm{HbA}_{1 \mathrm{c}}$ ) and the presence and number of diabetic complications.

\section{Subjects and methods}

Study design. This study was a double-blind, placebo-controlled, and flexible-dose escalation study which included 219 patients with Type II diabetes and ED from multiple clinical centres. After a 4-week run-in period, during which baseline data on sexual function were collected, patients entered a 12week double-blind treatment period. Following randomisation to sildenafil or matching placebo, patients returned for followup visits after $2,4,8$, and 12 weeks of treatment.
Inclusion criteria. To be eligible, participants had to be 37 years of age or older with a clinical diagnosis of ED and be in a stable relationship of more than 6 months duration with a female partner. Patients had to have a clinical diagnosis of Type II diabetes of at least 2 years' duration as defined by the National Diabetes Data Group [13], had to be at least 35 years of age at the time of diagnosis of diabetes, and must not have required insulin for at least 2 years after diagnosis. Diabetes had to be generally stable with $\mathrm{HbA}_{1 \mathrm{c}}$ concentrations of less than $11 \%$.

Major exclusion criteria. Patients with genital anatomical deformities, major psychiatric disorders, a history of alcoholism or substance abuse, ED as a result of spinal cord injury, a history of myocardial infarction, stroke, heart failure, or unstable angina within the past 6 months, a history of hypotension, or currently using nitrates were excluded. Also excluded were patients who had one of the following: Type I (insulin-dependent) diabetes mellitus, $\mathrm{HbA}_{1 \mathrm{c}}$ concentrations of $11 \%$ or more, recurrent hypoglycaemic episodes, severe disabling autonomic neuropathy, diabetes secondary to pancreatic damage, Cushing's syndrome, and acromegaly. Patients with cardiovascular disease were not specifically excluded, but were carefully considered for study entry because of the potential impact of resuming sexual activity and the mild and transient vasodilatory effects of sildenafil on blood pressure.

Informed consent and ethics committee approval. Written consent was obtained from each subject before screening procedures commenced. The study was carried out in compliance with Good Clinical Practice (GCP) standards and the World Medical Assembly Declaration of Helsinki and according to local laws and regulations relevant to the study of therapeutic agents in the countries of conduct: Denmark, Finland, France, Germany, Sweden, and United Kingdom.

Study drug. All patients started at a 50-mg dose of sildenafil citrate (VIAGRA, $n=110)$ or matching placebo $(n=109)$, with the option of adjusting the dose to 25 or $100 \mathrm{mg}$ based on efficacy and tolerability.

Study evaluations. The primary outcome measures were as follows:

International Index of Erectile Function (IIEF) [14]: week 0 and week 12 ;

Question 3 (assesses the ability to achieve an erection sufficient for sexual intercourse);

Question 4 (assesses the ability to maintain an erection after penetration).

The secondary outcome measures were as follows:

(1) Event Log of Erectile Function: pretreatment 4-week runin period through week 12 of treatment.

Completed by patients each time they engaged in sexual activity. This asked about response to study drug and success of intercourse attempts.

(2) Global Efficacy Question (GEQ), week 12;

This question asked "Has the treatment you have been taking over the past 4 weeks improved your erections?"

(3) IIEF domains [14], week 0 and week 12;

The IIEF consists of 15 questions that are grouped into 5 different domains:

Erectile Function, Questions 1 to 5 and 15 (score range, $1-30)$;

Intercourse Satisfaction, Questions 6 to 8 (score range, $0-15)$; 
Orgasmic Function, Questions 9 and 10 (score range, $0-10)$;

Sexual Desire, Questions 11 and 12 (score range, 2-10); Overall Satisfaction, Questions 13 and 14 (score range, $2-10)$.

Answers were scored from 1 (almost never/never) to 5 (almost always/always), with 0 indicating no sexual activity.

(4) Life Satisfaction Checklist [15], week 0 and week 12; this is an 8-item questionnaire assessing the patients' quality of life (life as a whole, sexual life, partnership relation, family life, contacts with friends, leisure situation, vocational situation, financial situation). Answers are scored from 1 (very dissatisfying) to 6 (very satisfying).

(5) Partner Questionnaire, week 12;

two questions are asked relating to the patients' ability to achieve and maintain an erection. Answers are scored as on the IIEF.

Statistical evaluation. We calculated the sample size needed to detect a statistical difference in the mean endpoint response for sildenafil (combined $25 \mathrm{mg}, 50 \mathrm{mg}$ and $100 \mathrm{mg}$ dose groups) and compared it with placebo. Based on a difference of 1.33 in mean scores and assuming a common standard deviation for sildenafil and placebo of 2.0, a sample size of 50 patients per treatment arm was sufficient to achieve a power of $90 \%$ to detect the specified difference between the two treatment groups using an approximation (two-sided, alpha $=0.05$ ) to the test comparing two means for normally distributed responses. In total, 220 (110 in each group) were randomized to sildenafil or placebo, which provided sufficient power for the primary analysis of efficacy and the analysis of covariance (including terms for treatment group, country, baseline value for efficacy variables, duration of ED, aetiology of ED, age and duration of diabetes).To determine if the effect of sildenafil was related to the degree of glycaemic control, data were subanalysed by $\mathrm{HbA}_{1 \mathrm{c}}$ concentration, using the median cutoff of $8.3 \%$, to obtain a group with fair control and a poorly controlled group.

Data were also subanalysed by the number of diabetic complications, which were divided into four categories: cardiovascular disease (angina, hypertension, congestive heart failure, myocardial infarction, coronary or peripheral artery disease), nephropathy (impaired renal function, albuminuria, microalbuminuria), neuropathy (peripheral neuropathy), and retinopathy (visual abnormalities, macular degeneration). Each category was only counted once, although patients could have more than one complication in a given category, particularly in the cardiovascular disease category. Subsequently, patients were subdivided into two groups, with either none or one or more diabetic complications.

Efficacy variables were analysed by ANCOVA. Each of the two primary efficacy variables (IIEF questions 3 and 4) was analysed separately, using univariate ANCOVA methods. Results were considered statistically significant with a $p$ value of less than 0.05 (using two-sided tests) in both analyses to show efficacy over placebo. The GEQ was analysed using logistic regression. The percentage of patients answering "yes" was estimated from the actual percentage and adjusted using covariates. The percentage of successful intercourse attempts was analysed for a difference between treatment groups using logistic regression. All hypotheses were tested for significance $(p<0.05)$ and were two-sided. SAS version 6.12 (SAS Institute, Cary, N.C., USA) was used for the statistical analyses.
Table 1. Demographic variables of patients at baseline

\begin{tabular}{|c|c|c|}
\hline & $\begin{array}{l}\text { Placebo } \\
(n=109)\end{array}$ & $\begin{array}{l}\text { Sildenafil } \\
(n=110)\end{array}$ \\
\hline Mean age, years (range) & $59.1(45-72)$ & $58.2(38-80)$ \\
\hline Mean weight, kg (range) & $88.2(62-121)$ & $88.1(60-146)$ \\
\hline $\begin{array}{r}\text { Race, \% } \\
\text { White } \\
\text { Black } \\
\text { Asian } \\
\text { Other }\end{array}$ & $\begin{array}{c}96.3 \\
0 \\
1.8 \\
1.8\end{array}$ & $\begin{array}{r}95.5 \\
1.8 \\
1.8 \\
0.9\end{array}$ \\
\hline $\begin{array}{l}\text { ED aetiology, \% } \\
\text { Non-psychogenic } \\
\text { Psychogenic } \\
\text { Mixed }\end{array}$ & $\begin{array}{r}69.7 \\
8.3 \\
22.0\end{array}$ & $\begin{array}{r}64.5 \\
3.6 \\
31.8\end{array}$ \\
\hline $\begin{array}{l}\text { Smoking status, \% } \\
\text { Ex-smoker } \\
\text { Never smoked } \\
\text { Smoker }\end{array}$ & $\begin{array}{l}50.5 \\
25.7 \\
23.9\end{array}$ & $\begin{array}{l}53.6 \\
24.5 \\
21.8\end{array}$ \\
\hline $\begin{array}{l}\text { Mean time since diagnosis of } \\
\text { ED, years (range) }\end{array}$ & $3.7(0.7-11.1)$ & $4.6(0.4-21)$ \\
\hline $\begin{array}{l}\text { Mean time since diagnosis of } \\
\text { Type II diabetes, years (range) }\end{array}$ & $9.7(1.0-28)$ & $10.1(2.0-34)$ \\
\hline $\begin{array}{l}\text { Diabetic complications, \% } \\
\quad 0 \\
1 \\
2 \\
3\end{array}$ & $\begin{array}{c}31.1 \\
52.3 \\
16.5 \\
0\end{array}$ & $\begin{array}{r}42.7 \\
40.9 \\
14.5 \\
1.8\end{array}$ \\
\hline Insulin used, \% & 36.7 & 31.8 \\
\hline $\begin{array}{l}\text { Concomitant illness, \% } \\
\text { Hypertension } \\
\text { Ischaemic heart disease } \\
\text { Hypercholesterolaemia }\end{array}$ & $\begin{array}{r}52.3 \\
2.8 \\
7.3\end{array}$ & $\begin{array}{r}40.0 \\
5.5 \\
8.2\end{array}$ \\
\hline $\begin{array}{l}\mathrm{HbA}_{1 \mathrm{c}} \text { concentration, median } \\
\text { (range) }\end{array}$ & $8.4(5.1-12.1)$ & $8.3(5.1-12.1)$ \\
\hline $\begin{array}{r}\% \mathrm{HbA}_{1 \mathrm{c}} \\
\leq 8.3 \% \\
>8.3 \%\end{array}$ & $\begin{array}{l}49.0 \\
51.0\end{array}$ & $\begin{array}{l}51.5 \\
48.5\end{array}$ \\
\hline Mean treatment duration, $d(S D)$ & $84.0 \pm 21.7$ & $85.9 \pm 25.9$ \\
\hline $\begin{array}{l}\text { Number of doses taken per } \\
\text { month, (SD) }\end{array}$ & $10.4 \pm 6.0$ & $10.9 \pm 6.0$ \\
\hline $\begin{array}{l}\text { Last dose taken }{ }^{\mathrm{a}}, \% \\
25 \mathrm{mg} \\
50 \mathrm{mg} \\
100 \mathrm{mg}\end{array}$ & $\begin{array}{c}0 \\
2.8 \\
95.4\end{array}$ & $\begin{array}{r}0.9 \\
20.0 \\
77.3\end{array}$ \\
\hline
\end{tabular}

Two patients in each treatment group were missing last dose information and were excluded from the percentage calculation

\section{Results}

Demographics. The baseline characteristics of men with ED randomised to placebo or sildenafil were largely similar, although there were some minor differences (Table 1). Most men in the sildenafil group $(85 / 110 ; 77.3 \%)$ preferred the $100-\mathrm{mg}$ dose of sildenafil over the lower doses. In comparison, $21.8 \%$ (24/110) and $0.9 \%$ (1/110) of patients used the 50$\mathrm{mg}$ and 25-mg dose of sildenafil, respectively.

Efficacy. After 12 weeks, there were marked improvements in the ability to achieve and maintain an 
Table 2. Efficacy parameters

\begin{tabular}{|c|c|c|c|c|c|c|c|c|c|c|c|c|c|c|c|}
\hline & \multicolumn{3}{|c|}{ All patients } & \multicolumn{3}{|c|}{$\mathrm{HbA}_{1 \mathrm{c}}<8.3 \%$} & \multicolumn{3}{|c|}{$\mathrm{HbA}_{1 \mathrm{c}} \geq 8.3 \%$} & \multicolumn{3}{|c|}{0 complications } & \multicolumn{3}{|c|}{$\geq 1$ complications } \\
\hline & $\mathrm{B}$ & $\mathrm{P}$ & $\mathrm{S}$ & $\mathrm{B}$ & $\mathrm{P}$ & $\mathrm{S}$ & $\mathrm{B}$ & $\mathrm{P}$ & $S$ & $\mathrm{~B}$ & $\mathrm{P}$ & $\mathrm{S}$ & $\mathrm{B}$ & $\mathrm{P}$ & $\mathrm{S}$ \\
\hline IIEF Q3,n & & 101 & 101 & - & 47 & 47 & - & 47 & 47 & - & 32 & 43 & - & 69 & 58 \\
\hline SEM & - & 0.22 & 0.23 & - & 0.34 & 0.40 & - & 0.37 & 0.36 & - & 0.41 & 0.43 & - & 0.30 & 0.32 \\
\hline IIEF Q4, $n$ & 100 & 101 & 47 & 47 & 46 & 47 & 32 & 43 & 69 & 57 & & & & & \\
\hline Mean score & 1.49 & 1.84 & $3.35^{\mathrm{a}}$ & 1.45 & 1.60 & $2.84^{\mathrm{b}}$ & 1.45 & 1.39 & $3.04^{\mathrm{a}}$ & 1.65 & 1.75 & $3.46^{\mathrm{a}}$ & 1.42 & 1.95 & $3.21^{\mathrm{a}}$ \\
\hline Mean score & 10.4 & 11.5 & $20.4^{\mathrm{a}}$ & 10.2 & 10.8 & $19.1^{\mathrm{a}}$ & 10. & 9.5 & $18.2^{\mathrm{a}}$ & 10.9 & 10.3 & $19.7^{\mathrm{a}}$ & 10.2 & 12.7 & $21.0^{\mathrm{a}}$ \\
\hline SEM & - & 1.17 & 1.24 & - & 1.78 & 2.03 & - & 1.95 & 1.95 & - & 2.21 & 2.33 & - & 1.61 & 1.72 \\
\hline $\begin{array}{l}\text { Successful } \\
\text { attempts, } n\end{array}$ & 84 & 82 & 40 & 35 & 37 & 40 & 24 & 40 & 58 & 50 & & & & & \\
\hline Estimated \% & 13.8 & 14.4 & $58.8^{\mathrm{a}}$ & 14.1 & 15.9 & $48.6^{\mathrm{c}}$ & $12.6-$ & 16.8 & $62.0^{\mathrm{a}}$ & 18.6 & 20.7 & $63.1^{\mathrm{c}}$ & 11.4 & 13.4 & $56.3^{\mathrm{a}}$ \\
\hline $95 \% \mathrm{CI}$ & - & $8.6-23$ & $48-69$ & - & $7.7-30$ & $34-63$ & - & $8.2-31$ & $45-76$ & - & $8.9-41$ & $45-79$ & - & $7.4-23$ & $43-69$ \\
\hline
\end{tabular}

$B$ baseline, $P$ placebo, $S$ sildenafil

${ }^{\mathrm{a}} p<0.0001 ;{ }^{\mathrm{b}} p<0.0002 ;{ }^{\mathrm{c}} p<0.005$

Table 3. Life satisfaction checklist

\begin{tabular}{lll}
\hline & Placebo & Sildenafil \\
\cline { 2 - 3 } & Mean score $^{\mathrm{a}}$ & \\
\hline Life as a whole & 4.9 & 4.97 \\
Sexual life & 2.55 & $3.79^{\mathrm{b}}$ \\
Partnership relation & 5.05 & 5.15 \\
Family life & 5.39 & 5.37 \\
Contact with friends & 5.18 & 5.13 \\
Leisure situation & 5.02 & 4.97 \\
Vocational situation & 4.41 & 4.63 \\
Financial situation & 4.59 & 4.49
\end{tabular}

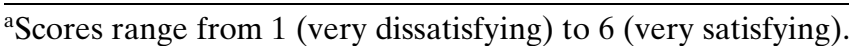
${ }^{\mathrm{b}} p<0.0001$ vs placebo

erection (Table 2), with the mean scores for IIEF Q3 and Q4 significantly higher in the sildenafil group compared with the placebo group. Efficacy was similar between treatment groups when patients were subanalysed by $\mathrm{HbA}_{1 \mathrm{c}}$ concentration or the number of diabetic complications. The median $\mathrm{HbA}_{1 \mathrm{c}}$ concentration at baseline was $8.3 \%$, and the number of diabetic complications was classified as 0 and greater than 1 since the number of patients with two or more complications was small ( $<20 \%$, Table 1$)$. Affirmative responses to the GEQ ("Has treatment improved your erections?") were significantly higher in the sildenafil group, with more than $65 \%$ of patients answering in the affirmative compared with only $11 \%$ in the placebo group (Fig. 1). Although there was no difference in efficacy when data were subanalysed by $\mathrm{HbA}_{1 \mathrm{c}}$ concentration, for most efficacy parameters patients with no diabetic complications seemed to respond slightly better than those with one or more complications.

After 12 weeks of sildenafil treatment, scores of erectile function were markedly improved compared with placebo, with no differences in efficacy between

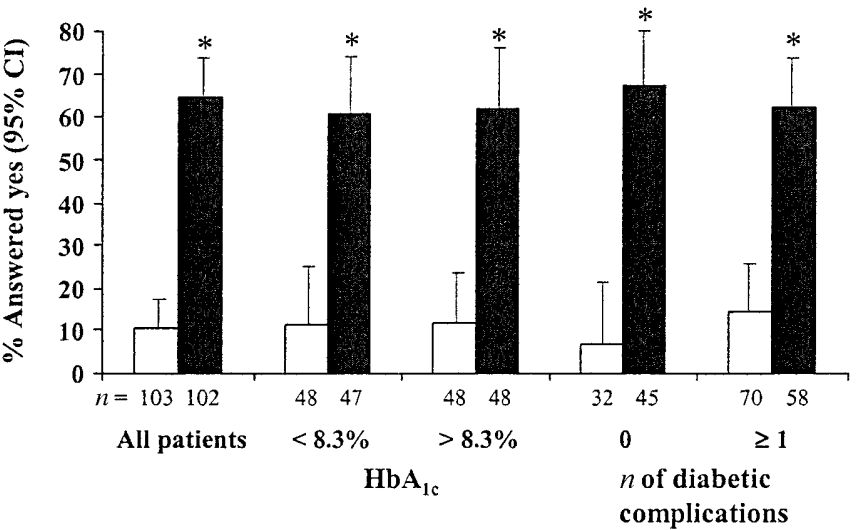

Fig. 1. After 12 weeks of treatment, the percentage of patients answering "yes" to the GEQ ("Did treatment improve your erections?") was significantly improved in patients receiving sildenafil (ם) compared with those receiving placebo ( $\square$, $p<0.0001)$. Patients with no diabetic complications responded slightly better than those with one or more complications

the different subgroups (Table 2). Similarly, the estimated number of successful intercourse attempts was improved in patients receiving sildenafil compared with those receiving placebo $(p<0.0001$, Table 2). Again, sildenafil was efficacious independent of $\mathrm{HbA}_{1 \mathrm{c}}$ concentration and number of diabetic complications. In addition, using the Life Satisfaction Checklist, a quality-of-life questionnaire, sildenafil was shown to improve scores for sexual life 1.5-fold over placebo treatment (Table 3); other domains showed no significant differences between sildenafil and placebo.

Adverse events. The most common treatment-related adverse events (AEs) included headache and flushing; all other AEs occurred in less than $5 \%$ of the patients (Table 4). All AEs were transient and mild to 
Table 4. Treatment-related adverse events

\begin{tabular}{lcc}
\hline & Placebo & Sildenafil \\
\hline Evaluable subjects, $n$ & 109 & 110 \\
Completed study, \% & 92 & 93 \\
Number of AEs, $n$ & 11 & 65 \\
Subjects with AEs, \% & 6.4 & 37.3 \\
Subjects with serious AEs, \% & 0 & 0 \\
Subjects with severe AEs, \% & 0 & 0.9 \\
Subjects discontinued due to AEs, \% & 0 & 0 \\
AEs & & \\
Headache, \% & 3.7 & 18.2 \\
Flushing, \% & 0 & 14.5 \\
Dyspepsia, \% & 0.9 & 1.8 \\
Abnormal vision, \% & 0 & 4.5 \\
\hline
\end{tabular}

moderate in nature, and the rate of discontinuations due to AEs of all causalities was low $(1.8 \%$ in both treatment groups).

\section{Discussion}

This 12-week controlled trial shows that sildenafil is well tolerated and markedly improves the ability to achieve and maintain an erection, increases the number of successful attempts at intercourse, and improves sex-related quality of life in Type II diabetic men with ED. Men with diabetes have an approximately threefold higher risk for ED than men without diabetes [3], and it has been shown that erectile function decreases with lack of glycaemic control (e.g., with increased blood glucose and $\mathrm{HbA}_{1 \mathrm{c}}$ concentration) [5]. Advanced glycation end-products accumulating in tissue proteins are a result of increased blood glucose and play a part in many of the complications of diabetes. They have also been shown to decrease nitric oxide activity and modulate endothelium-dependent relaxation and thus could adversely affect nitric oxide-signalling mechanisms within the corpora cavernosa [16]. In a convenience sample of men with Type II diabetes, a multivariate analysis showed that $\mathrm{HbA}_{1 \mathrm{c}}$ was an independent predictor of erectile function and that patients with a mean $\mathrm{HbA}_{1 \mathrm{c}}$ concentration of $6.9 \%$ had no signs of neuropathy and scored 20.1 points on the erectile function domain score, with only $10 \%$ of patients using insulin. In comparison, patients with mean $\mathrm{HbA}_{1 \mathrm{c}}$ concentrations of $8.8 \%$ had signs of neuropathy and scored only 14.7 points on the erectile function domain score, with $70 \%$ of patients using insulin [2]. In our study, sildenafil (25-100 mg) was an effective oral therapy for men with Type II diabetes as determined by the IIEF (questions 3 and 4, erectile function domain), the GEQ, and the percentage of successful attempts at intercourse. Efficacy was independent of $\mathrm{HbA}_{1 \mathrm{c}}$ concentrations $(\leq 8.3 \%$ or $>8.3 \%$ ). However, men with fewer diabetic complications seemed to respond marginally better to IIEF ques- tions 3 and 4 and the GEQ and reported slightly more successful attempts at intercourse than the men who had more conditions typically associated with diabetes.

In a previous study of diabetic patients, sildenafil was shown to be an effective and well tolerated treatment in a mixed (Type I and II) group of 268 diabetic men with ED [1]. In this patient group, efficacy of sildenafil was independent of age, duration of ED, and duration of diabetes, and erections were improved by $56 \%$ with sildenafil, compared with $10 \%$ for placebo. Thus, our study has shown better efficacy of sildenafil possibly due to a more homogenous group, consisting exclusively of Type II diabetic men.

The efficacy and safety of sildenafil have been assessed from more than 11000 patient-years of observation in controlled clinical trials, several of which focused on and/or included men with diabetes; moreover, since its regulatory approval in the United States in March 1998, sildenafil has been prescribed to more than 10 million patients worldwide [17]. The safety profile of sildenafil in this study of men with ED and Type II diabetes is in agreement with previous reports, in which the most common AEs associated with use of sildenafil in flexible-dose studies were headache $(16 \%)$, flushing $(10 \%)$, dyspepsia (7\%), and visual disturbances (3\%), all consistent with the known pharmacologic effects of the drug [18]. These effects were generally transient and mild to moderate in nature and the rate of discontinuations due to AEs of all causalities was similar for patients receiving placebo $(1.8 \%)$ or sildenafil $(1.8 \%)$. All clinical studies conducted so far have shown that the incidence of AEs and the rate of discontinuations due to AEs is similar in patients with diabetes compared with patients without diabetes $(<2 \%)$ [19].

When treating patients with diabetes, it is also important to establish that AEs related to metabolic function, which could exacerbate diabetes, do not occur. There is no indication from clinical trial data that sildenafil adversely affects blood glucose concentrations in patients with diabetes. Furthermore, in a previously published study in 21 men with diabetes, no clinically important changes in laboratory test results were observed, suggesting that sildenafil did not impair metabolic control [20].

In summary, this first trial of sildenafil in men with Type II diabetes showed a better response rate than previously reported in a mixed diabetic population. Because poorly controlled diabetes is often associated with diabetic neuropathy [21] and peripheral vascular disease [22], both of which can increase the risk of ED, it is encouraging that treatment with sildenafil was able to improve erections in men with Type II diabetes independent of the degree of glycaemic control or the presence of neuropathic and vascular complications. Moreover, the favourable tolerability coupled with a mechanism of action requiring 
sexual stimulation, are desirable characteristics for a successful treatment for ED.

Acknowledgements. Clinical investigators: C.E.S. Mogensen, Århus, Denmark; A. Larsen, Helsinki, Finland; C. Jaffiol, Montpellier, France; D. Malgrange, Reims, France; G. Narboni, Besançon, France; J. Rollet, Bron, France; J-L. Selam, Paris, France; R. Selam, Paris, France; K-P. Jünemann, Mannheim, Germany; F. Merfort, Mönchengladbach, Germany; R. Probst, Marl , Germany; J. Rassweiler, Heilbronn, Germany; D. Ziegler, Düsseldorf, Germany; P. Ohman, Linkoping, Sweden; S. Atkin, Hull, UK; A.J.M. Boulton, Manchester, UK; B. Fisher, Paisely, UK; C. Johnston, Hemel Hempstead, UK; S. Page, Nottingham, UK; K. MacLeod, Exeter, UK.

\section{References}

1. Rendell MS, Rajfer J, Wicker PA et al. (1999) Sildenafil for treatment of erectile dysfunction in men with diabetes. JAMA 281: 424-426

2. Romeo JH, Seftel AD, Madhun ZT et al. (2000) Sexual function in men with diabetes type 2: association with glycemic control. J Urol 163: 788-791

3. Feldman HA, Goldstein I, Hatzichristou DG, Krane RJ et al. (1994) Impotence and its medical and psychosocial correlates: results of the Massachusetts Male Aging Study. J Urol 151: 54-61

4. Lee WH, Kim YC, Choi HK (1994) Psychogenic versus primary organic impotence. Int J Impot Res 6: 93-97

5. Klein R, Klein BE, Lee KE et al. (1996) Prevalence of selfreported erectile dysfunction in people with long-term IDDM. Diabetes Care 19: 135-141

6. Cummings MH, Alexander WD (1999) Erectile dysfunction in patients with diabetes. Hosp Med 60: 638-644

7. UK Prospective Diabetes Study Group (1998) Tight blood pressure control and risk of macrovascular and microvascular complications in type 2 diabetes: UKPDS 38. BMJ 317: 703-713

8. Linet O, Ogrine F (1996) Efficacy and safety of intracavernosal alprostadil in men with erectile dysfunction. N Engl J Med 334: 873-877

9. Aloni R, Heller L, Keren O et al. (1992) Noninvasive treatment for erectile dysfunction in the neurogenically disabled population. J Sex Marital Ther 18: 243-249
10. Padma-Nathan H, Hellstrom W, Kaiser F (1997) Treatment of men with erectile dysfunction with transurethral alprostadil. N Engl J Med 336: 1-7

11. Goldstein I, Lue TF, Padma-Nathan H et al. (1998) Oral sildenafil in the treatment of erectile dysfunction. $\mathrm{N}$ Engl J Med 338: 1397-1404

12. Boolell M, Gepi-Attee S, Gingell JC et al. (1996) Sildenafil, a novel effective oral therapy for male erectile dysfunction. Brit J Urol 78: 257-261

13. National Diabetes Data Group (1979) Classification and diagnosis of diabetes mellitus and other categories of glucose intolerance. Diabetes 28: 1039-1057

14. Rosen RC, Riley A, Wagner G et al. (1997) The International Index of Erectile Function (IIEF): A multidimensional scale for assessment of erectile dysfunction. Urology 49: 822-830

15. Fugl-Meyer AR, Lodnert G, Bränholm I-B et al. (1997) On life satisfaction in male erectile dysfunction. Int $\mathrm{J}$ Impot Res 9: 141-148

16. Seftel AD, Vaziri ND, Ni Z, Razmjouei K et al. (1997) Advanced glycation end products in human penis: elevation in diabetic tissue, site of deposition, and possible effect through iNOS or eNOS. Urology 50: 1016-1026

17. Sadovsky R, Miller T, Moskovitz M (2001) Three-year update of sildeanfil citrate (Viagra) efficacy and safety. Int J Clin Pract 55: 115-128

18. Morales A, Gingell C, Collins M et al. (1998) Clinical safety of oral sildenafil citrate (VIAGRA) in the treatment of erectile dysfunction. Int J Impot Res 10: 69-74

19. Guay AT, Blonde L, Siegel R et al. (2000) Safety and tolerability of sildenafil citrate for treatment of erectile dysfunction in men with type 1 and type 2 diabetes mellitus. Diabetes 49 [Suppl 1]:363

20. Price DE, Gingell JC, Gepi-Attee S et al. (1998) Sildenafil: study of a novel oral treatment for erectile dysfunction in diabetic men. Diabet Med 15: 821-825

21. Bemelmans BL, Meuleman E, Doesburg WH (1994) Erectile dysfunction in diabetic men: the neurological factor revisited. J Urol 151: 884-889

22. Kadioglu A, Erdogru T, Karsidag et al. (1995) Evaluation of penile arterial system with colour Doppler ultrasonography in nondiabetic and diabetic males. Eur Urol 27: 311-314 